\title{
Optimization of Placement and Size of Distribution Generators Using Quantum Genetic Algorithms to Improve Power Quality in Bali Distribution Networks
}

\author{
Yanu Prapto Sudarmojo ${ }^{1^{*}}$, Antonius Ibi Weking ${ }^{2}$ \\ ${ }^{1,2}$ Departement of Electrical Engeneering \\ Faculty of Engeneering \\ Udayana University \\ Bali- Indonesia 80361 \\ *yanuprapto@yahoo.com
}

\begin{abstract}
Bali is a tourist area with resources originating from Java and several large-scale factories that use oil and gas, which until now still need more electricity. The addition of small-scale generators in Bali is very helpful where economic benefits are distribution costs and reduction in transmission costs, electricity costs and fuel savings. Technically, DG distributors must be done correctly and optimally from size or location so as to provide maximum results from an economic perspective, minimizing electricity losses and increasing the voltage profile which results in an increase in electricity quality. For this reason, this study will use heuristic optimization using the Quantum Genetic Alghorithm method to place generators distributed to the Bali Electricity Network. To calculate electricity losses and voltage profiles, the method used to solve them is the Newton Raphson method.

A result of this study, DG was installed in a feeder located in Abang District, Karangasem Regency where Abang Feeder had a total of 431 buses that were part of the Bali Distribution System. By using QGA, DG is installed on buses $1,5,7$, and 302 with capacities of each DG is $0.374 \mathrm{MW}, 1.894 \mathrm{MW}, 1.988 \mathrm{MW}$ and $0.500 \mathrm{MW}$, after installation of DG, the voltage profile can be repaired. The voltage profile for several buses to Abang Feeder can be fixed from $0.83 \mathrm{pu}$ to $0.98 \mathrm{pu}$. Electricity losses from 1.105 MW to 0.234 MW
\end{abstract}

\section{Index Term : Optimation, Distributed Generator (DG), Quantum Genetic Alghorithm, Voltage Profile, Electricity Loss.}

\section{INTRODUCTION}

Electricity requirements in Bali that are increasing every year must be balanced with an increase of electricity supply. Concerns about economic problems and environmental pollution encourage to increasing in development that supports small-scale generators to be connected close to distribution networks or near load centers. [1][2] To meet this urgent requirements, the distribution of small-scale generators from renewable energy such as Micro Hydro Power Plants, etc. which are connected to the PLN electricity network is due to the decreasing voltage in several loads which increases power losses. PLN standardizes the normal voltage from $0.9 \mathrm{pu}$ to $1.05 \mathrm{pu}$. where in some of the load stress is brought in $0.9 \mathrm{pu}$ and this matter needs to be stabilized. [3]
Installation of Distribution Generator (DG) has several advantages in economic, environmental and technical terms. Benefits from economic is reduce transmission distribution and costs, electricity prices and fuel economy. [4][5][6] Planning an electrical system with distribution generator depend of several factors, such as: the number and capacity of the unit, the best location, the best technology to be used, the network connection method. For large networks, software is needed to calculate it.

This research to use Quantum Genetic Algorithm (QGA) combined with Newton Raphson power flow to optimize the placement and size of Distribution Generators (DG) in the Bali distribution system to improve the quality of electric power. 


\section{METHOD}

A. Power System Distribution Network.

Electric power centers are generally located far from the center of the load. Electrical energy produced by the generation center is channeled through the transmission network. Generator of generator voltage is relatively low $(6 \mathrm{kV}-24 \mathrm{kV})$ where this voltage is raised with a power transformator to a higher voltage of $150 \mathrm{kV}-500$ $\mathrm{kV}$. The purpose of increasing this voltage, in addition to enlarging the conductivity of the channel (directly proportional to the square of the voltage), is also to minimize power losses and voltage losses in the transmission line. The reduction in voltage from high extra high voltage networks before to consumers is done twice. The first is done at the substation (GI), reducing the voltage from $500 \mathrm{kV}$ to $150 \mathrm{kV}$ or from $150 \mathrm{kV}$ to $70 \mathrm{kV}$. The second is done at a distribution substation from $150 \mathrm{kV}$ to $20 \mathrm{kV}$ or from $70 \mathrm{kV}$ to $20 \mathrm{kV}$. The power line from the source of the power plant to the last transformator, often referred to as the transmission line, while from the last transformator, until the last consumer is called the distribution channel or primary channel. The distribution system voltage can be grouped into 2 major parts, namely:[7]

1. Primary Distribution $(20 \mathrm{kV})$

The $20 \mathrm{kV}$ distribution network is often called the Medium Voltage Distribution System. Networks In the medium voltage distribution system (Primary $20 \mathrm{kV}$ ) can be grouped into five models, namely the Radial Network, The Connecting Network (Tie Line), Circle Network (Loop), Spindle Network and Cluster Systems.

2. Secondary Distribution $(380 / 220 \mathrm{~V})$.

The 380 / 220V distribution network is often called a secondary distribution network or called the 380 / 220V Low Voltage Network.

B. Newton Raphson Method

Newton Raphson (N_R) is a method that is often used in power flow analysis to calculate system losses and stresses on each system bus. In the use of several things known as: [8]

Power Injection

Power on Bus i :

$$
S_{i}^{*}=V_{i}^{*} \sum_{k=1}^{n} Y_{i k} V_{k}
$$

Updated variables after $\mathrm{k}$ iterations :

$$
\begin{gathered}
\Delta \delta_{i}^{(k+1)}=\Delta \delta_{i}^{(k)}+\Delta \delta_{i} \ldots \\
\left|V_{i}\right|^{(k+1)}=\left|V_{i}\right|^{(k)}=\Delta\left|V_{i}\right|
\end{gathered}
$$

Channel power flow :

Power flow from bus $i$ ke bus $j$ :

$$
S_{i j}=V_{i} I_{i j}^{*}=V_{i}\left(\frac{V_{i}-V_{j}}{Z_{i j}}+V_{i} Y_{i j 0}\right) .
$$

Power flow from bus $j$ ke bus $i$ :

$$
S_{j i}=V_{j} I_{j i}^{*}=V_{i}\left(\frac{V_{j}-V_{i}}{Z_{j i}}+V_{j} Y_{j i 0}\right) \ldots
$$

Channel losses :

$$
\begin{array}{r}
P_{i}=\sum_{i=1}^{\text {bus no }} \sum_{j=1}^{\text {bus no }}\left(S_{i j}+S_{j i}\right) \\
=\sum_{i=1}^{b u s} n o \sum_{j=1}^{b u s n o}\left\{\left(P_{i j}+Q_{i j}\right)+\left(P_{j i}+\right.\right. \\
\left.\left.Q_{j i}\right)\right\} \quad \ldots \ldots \ldots \ldots \ldots \ldots \ldots(6)
\end{array}
$$

\section{Quantum Genetic Algorithm (QGA)}

Quantum Genetic Method Algorithm is based on the concepts of quantum bits (cubite) and superpositions of quantum mechanical forms. The smallest information is stored in two forms of quantum numbers called quantum bits or cubits. Kubit may be in the ' 1 ' or ' 0 ' state / status, or the superposition of both. The status of the cubite can be shown as the following equation: [9][10]

$$
|\psi\rangle=|\alpha|^{2}+|\beta|^{2}
$$

Where $\alpha$ and $\beta$ is a complex number that corresponds to the probability of the amplitude of the state. Normalization from the states is:

$$
|\alpha|^{2}+|\beta|^{2}=1
$$

QGA is based on the concept of cubite. One cubit is defined to consist of a number pair $(\alpha, \beta)$ as follows :

$$
\left[\begin{array}{l}
\alpha \\
\beta
\end{array}\right]
$$

Which is the equation of the equation (8) dan (9). For $\mathrm{m}$ cubits represented as the following matrix below :

$$
\left[\begin{array}{c|c|c|c}
\alpha_{1} & \alpha_{2} & \ldots & \alpha_{m} \\
\beta_{1} & \beta_{2} & \ldots & \beta_{m}
\end{array}\right]
$$

Where,

$$
\left|\alpha_{i}\right|^{2}+\left|\beta_{i}\right|^{2}=1, \mathrm{i}=1,2,3 \ldots \mathrm{m}
$$

This representation has the advantage of being able to represent several superpositions of circumstances. For an easier understanding, here 
the following example: three cubits with three pairs of numbers as follows:

$$
\left[\begin{array}{c|c|c}
\frac{1}{\sqrt{2}} & \frac{\sqrt{3}}{2} & 1.0 \\
\frac{1}{\sqrt{2}} & \frac{1}{2} & 0
\end{array}\right]
$$

The three pairs of numbers above can be represented as follows:

$$
\begin{aligned}
& \frac{\sqrt{3}}{2 \sqrt{2}}|000\rangle+0|001\rangle+\frac{1}{2 \sqrt{2}}|010\rangle+0|001\rangle+ \\
& \frac{\sqrt{3}}{2 \sqrt{2}}|100\rangle+0|101\rangle+\frac{1}{2 \sqrt{2}}|110\rangle+0|111\rangle
\end{aligned}
$$

This result shows that the probability of state $|000\rangle,|010\rangle,|100\rangle$ and $|110\rangle$ is $\frac{3}{8}, \frac{1}{8}, \frac{3}{8}$ dan $\frac{1}{8}$.

Three cubite systems from equation (11) have four types of information at the same time. Evolutionary calculations by representing cubits that have diverse characteristics, are better than the classical approach because they can represent every situation. One cubit string like equation (11) can represent four states (status). Convergence can also be obtained by qubit representation. As $|\alpha|^{2}$ or $|\beta|^{2}$ the approach to 1 or 0 , converges the qubit string to a single state and the property of diversity disappears gradually. That means, qubit representations can have two characteristics of exploration and exploitation simultaneously.

\section{Rotation Gate /Q-gate}

Gate Rotation (Quantum-gate) is defined as the operator of the QGA variation, where the updated qubit operation must meet the normalization conditions, $\left|\alpha^{\prime}\right|^{2}+\left|\beta^{\prime}\right|^{2}=1$, where $\alpha^{\prime}$ and $\beta^{\prime}$ are updated qubit values.

Rotation Gate Equation as follows:

$$
\left[\begin{array}{l}
\alpha_{j}(t+1) \\
\beta_{j}(t+1)
\end{array}\right]=\boldsymbol{R}_{\boldsymbol{i}}(\boldsymbol{t}) \times\left[\begin{array}{l}
\alpha_{j}(t) \\
\beta_{j}(t)
\end{array}\right](j=1,2, . .)
$$

$$
\boldsymbol{R}_{\boldsymbol{i}}(\boldsymbol{t})=\left[\begin{array}{cc}
\cos \Delta \theta_{i} & -\sin \Delta \theta_{i} \\
\sin \Delta \theta_{i} & \cos \Delta \theta_{i}
\end{array}\right](i=1,2, n)
$$

$\Delta \theta_{i}$ is the angle of rotation (figure 1) of each member of the population. Rotation angle $\Delta \theta_{i}$ is related to differences in normalization $\Delta f_{i}$ between the achievements of each member of the population and the best optimal global.

Equation for $\Delta \theta_{i}$ :
$\Delta \theta_{i}=\Delta f_{i} \times \operatorname{sign}\left(\alpha_{b}-\alpha_{j}\right) \times \operatorname{sign}\left[\beta_{j} \times\right.$ $\left.\sin \Delta f_{-} i-\alpha_{-} j \times\left(1-\cos \Delta \mathrm{f}_{\mathrm{i}}\right)\right]$.

where :

$\Delta f_{i}=\pi \times\left(1-\frac{f(b)}{f\left(p_{i}(t)\right.}\right)(i=1,2, \ldots, n)$

$\operatorname{sign}\left(\alpha_{b}-\alpha_{j}\right)=$

$\left\{\begin{array}{l}+1 \text { if } \alpha_{b} \geq \alpha_{j} \\ -1 \text { if } \alpha_{b}<\alpha_{j}\end{array}\right.$

$\operatorname{sign}\left[\beta_{j} \times \sin \Delta f_{i}-\alpha_{j} \times\left(1-\cos \Delta f_{i}\right)\right]$

$=\left\{\begin{array}{l}+1 \text { if } \beta_{j} \times \sin \Delta f_{i} \geq \alpha_{j} \times\left(1-\cos \Delta f_{i}\right) \\ -1 \text { if } \beta_{j} \times \sin \Delta f_{i}<\alpha_{j} \times\left(1-\cos \Delta f_{i}\right)\end{array}\right.$

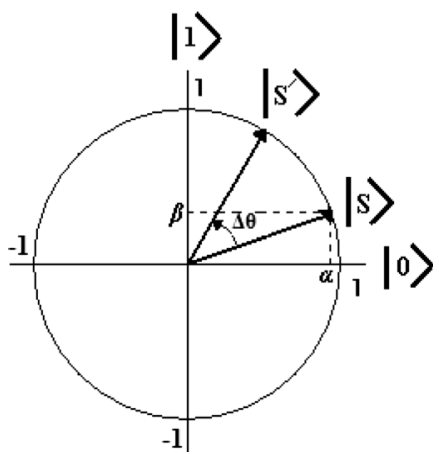

Fig. 1. Basic of Quantum bits (cubite)

D. Problems in formulation :

Objective Function

$\min \left\{P_{i}=\sum_{i=1}^{b u s} n o \sum_{j=1}^{b u s} n o\left(S_{i j}+\right.\right.$ $\left.\left.S_{j i}\right)\right\}$

Voltage Limitation

$\left|V_{i \text { min }}\right| \leq\left|V_{i}\right| \leq\left|V_{i_{\text {max }}}\right|$

DG Capacity Limitation

$\mathrm{P}_{\mathrm{DG} \text { min }} \leq \mathrm{P}_{\mathrm{DG}} \leq \mathrm{P}_{\mathrm{DG} \max }$

E. QGA implementation for optimization of location and size of DG.

1. $\mathrm{t}=0$

2. Initialize a population from $\mathrm{n}$ population (qubit string)

$$
\mathrm{Q}(0)=\left\{\mathrm{q}_{1}(0), \mathrm{q}_{2}(0), \cdots, \mathrm{q}_{\mathrm{n}}(0)\right\}
$$

Every qubit string representating :

$$
\mathrm{q}_{1}(0)=\left[\left|\begin{array}{l}
\alpha_{1}(0) \\
\beta_{1}(0)
\end{array}\right|\left|\begin{array}{l}
\alpha_{2}(0) \\
\beta_{2}(0)
\end{array}\right| \cdots\left|\begin{array}{l}
\alpha_{\mathrm{m}}(0) \\
\beta_{\mathrm{m}}(0)
\end{array}\right|\right]
$$

3. For all qubit strings initialize amplitude amplification at: 


$$
\mathrm{q}_{1}(0)=\left|\begin{array}{ccc}
\frac{1}{\sqrt{2}} & \frac{1}{\sqrt{2}} & \cdots \\
\frac{1}{\sqrt{2}} & \frac{1}{\sqrt{2}} & \cdots
\end{array}\right|
$$

4. Create randomly binary solutions with observing state $\mathrm{Q}(0)$ :

$$
\mathrm{P}(0)=\left\{\mathrm{p}_{1}(0), \mathrm{p}_{2}(0), \cdots, \mathrm{p}_{\mathrm{n}}(0)\right\}
$$

In this study, each DG is representative of an 8-bit binary number. MSB signifies where the DG is located. If the bit is 1 , DG will appear on the bus and DG output will be determined from the remaining 7 bits and also based on Pmin and Pmax from the input parameter matrix. If $\mathrm{MSB}=0$, the DG will not appear on the bus but as a load bus. Assess each $\mathrm{p}_{1}(0)(\mathrm{i}=1,2, \cdots, \mathrm{n})$ and prepare the data bus matrix.

5. Using the data bus, run the load flow and get the loss.Hitung fungsi objektif dan menyimpan nilai fitnessnya.

6. Perform steps 5-7 for each member of the population.

7. Find members of the population that have the highest objective function and are stored in the winner's place (iteration).

8. Next Iteration $(\mathrm{t}=\mathrm{t}+1)$

9. Generate the next population from the existing population with the rotation of each existing member so that the new generation gets closer to the winner, see figure 1 . Rotation is solved by the rotation of the matrix which has been calculated through equations (12) $-(17)$

10. Preform steps 4, 5, dan 6 as much as needed.

11. The most optimum solution is the last iteration.

\section{RESULT AND DISCUSION}

\section{A. Measurement and Location Data}

This study uses measurement data and secondary data on feeder Abang located in the eastern part of Bali province precisely in Karangasem Regency. Feeders who are in the area of PT. PLN (Persero) This East Bali Area has a total channel length of $207.946 \mathrm{Km}$. The total number of buses found in Penyulang Abang is 431 with the system working on a $20 \mathrm{kV}$ system with an electrical power supply from the GI Amlapura of $150 \mathrm{kV}$ then connected to the GI transformer to be reduced to $20 \mathrm{kV}$. [11]

Abang feeder is a feeder that uses a radial configuration type where between the point of the power source and the load point is in a straight line. The point of the electricity source and the end point in the feeder has a distance of 207.946 $\mathrm{Km}$, because the distance decreases the voltage profile.

TABLE 1

\section{LOAD DATA VOLTAGE BELOW 0.9 PU}

\begin{tabular}{|c|c|c|c|c|c|c|c|}
\hline \multirow{2}{*}{ BUS } & BUS & \multirow{2}{*}{ MAG } & \multirow{2}{*}{ ANG } & \multicolumn{2}{|c|}{ LOAD } & \multicolumn{2}{c|}{ GENERATOR } \\
\cline { 5 - 8 } & INPUT & & & MW & Mvar & MW & Mvar \\
\hline 319 & 401 & 0.83 & -5.9 & 0.024 & 0.015 & 0 & 0 \\
\hline 249 & 402 & 0.86 & -4.9 & 0 & 0 & 0 & 0 \\
\hline 250 & 403 & 0.83 & -6.1 & 0.026 & 0.016 & 0 & 0 \\
\hline 251 & 404 & 0.86 & -4.9 & 0 & 0 & 0 & 0 \\
\hline 252 & 405 & 0.85 & -5.4 & 0.011 & 0.007 & 0 & 0 \\
\hline 256 & 406 & 0.86 & -4.9 & 0 & 0 & 0 & 0 \\
\hline 255 & 407 & 0.84 & -5.9 & 0.02 & 0.013 & 0 & 0 \\
\hline 259 & 408 & 0.86 & -4.9 & 0 & 0 & 0 & 0 \\
\hline 257 & 409 & 0.86 & -4.9 & 0 & 0 & 0 & 0 \\
\hline 258 & 410 & 0.85 & -5.4 & 0.01 & 0.006 & 0 & 0 \\
\hline 323 & 411 & 0.86 & -4.9 & 0 & 0 & 0 & 0 \\
\hline 324 & 412 & 0.85 & -5.3 & 0.009 & 0.006 & 0 & 0 \\
\hline 260 & 413 & 0.86 & -4.9 & 0 & 0 & 0 & 0 \\
\hline 262 & 414 & 0.85 & -4.9 & 0 & 0 & 0 & 0 \\
\hline 336 & 415 & 0.85 & -5 & 0.003 & 0.002 & 0 & 0 \\
\hline 326 & 416 & 0.86 & -4.9 & 0 & 0 & 0 & 0 \\
\hline 261 & 417 & 0.85 & -5.1 & 0.004 & 0.003 & 0 & 0 \\
\hline 330 & 418 & 0.86 & -4.9 & 0 & 0 & 0 & 0 \\
\hline 328 & 419 & 0.85 & -5.2 & 0.007 & 0.004 & 0 & 0 \\
\hline 333 & 420 & 0.86 & -4.9 & 0 & 0 & 0 & 0 \\
\hline 334 & 421 & 0.83 & -6 & 0.024 & 0.15 & 0 & 0 \\
\hline 343 & 422 & 0.86 & -4.9 & 0 & 0 & 0 & 0 \\
\hline 341 & 423 & 0.86 & -4.9 & 0 & 0 & 0 & 0 \\
\hline 340 & 424 & 0.85 & -5.1 & 0.004 & 0.003 & 0 & 0 \\
\hline 347 & 425 & 0.85 & -4.9 & 0 & 0 & 0 & 0 \\
\hline 346 & 426 & 0.83 & -6 & 0.024 & 0.015 & 0 & 0 \\
\hline 350 & 427 & 0.86 & -4.9 & 0 & 0 & 0 & 0 \\
\hline 348 & 428 & 0.86 & -4.9 & 0 & 0 & 0 & 0 \\
\hline 263 & 429 & 0.85 & -5.1 & 0.004 & 0.003 & 0 & 0 \\
\hline 253 & 430 & 0.86 & -4.9 & 0 & 0 & 0 & 0 \\
\hline 252 & 431 & 0.83 & -6 & 0.024 & 0.015 & 0 & 0 \\
\hline & & & & & & & \\
\hline
\end{tabular}

Based on the simulation using the lowest voltage ETAP profile on feeder brother is equal to 0.83 p.u or $16.6 \mathrm{kV}$ found on buses 401, 403, 421, 426 and 431 with a total power loss of $1.105 \mathrm{MW}$. The allowable stress profile is between $0.9-1.05$ or $18 \mathrm{kV}-21 \mathrm{Kv}$. Because of these problems, the stress profile must be improved by installing several DGs on several buses with certain capacities so that a bad voltage profile can achieve the allowable voltage profile value.

\section{B. Field data testing}

Measurement data and secondary data on Abang feeder located in the eastern part of Bali province precisely in Karangasem Regency. Feeders who are in the area of PT. PLN (Persero) East Bali Area has a total channel length of 207.946 Km.[11] The total number of buses found in Abang feeder is 431. Abang feeder are feeders who use radial configuration types where between the point of the power source and the load point are in a straight line. Based on the simulation using the lowest voltage ETAP profile on feeder brother is $0.83 \mathrm{p} . \mathrm{u}$ or $16.6 \mathrm{kV}$ found on 
buses 401, 403, 421, 426 and 431. By using the QGA program the results obtained are as follows:

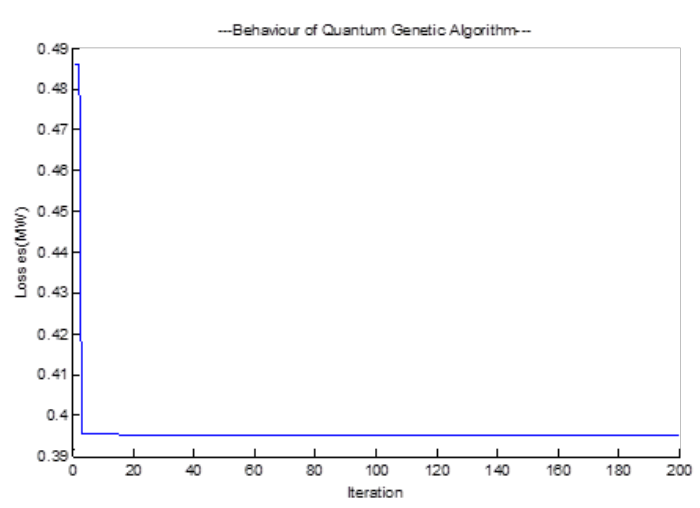

Fig. 2. Graphics of Abang Feeder Simulation Results With QGA

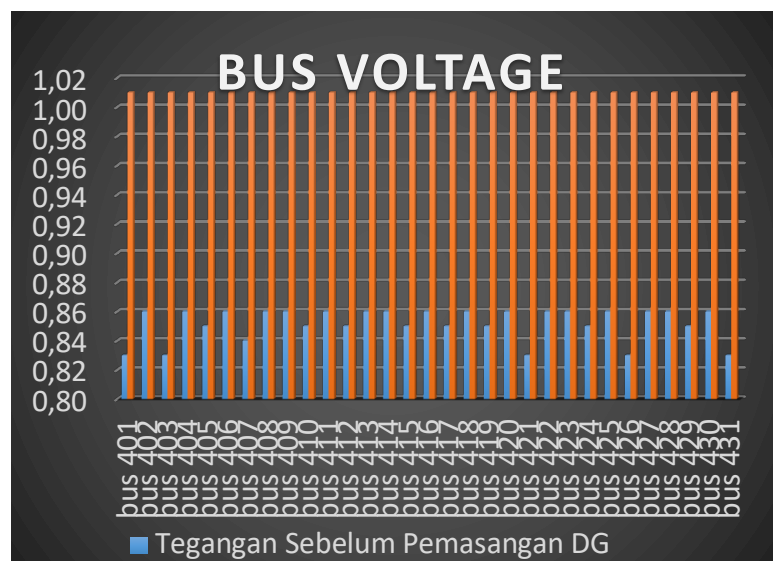

Fig. 3. Voltage Repair with QGA

From the results of running the program of Distribution Generator (DG) is installed on buses $1,5,7$ and 302 with a sequence of capacities of $0.374 \mathrm{MW}, 1.894 \mathrm{MW}, 1.988 \mathrm{MW}$ and $0.500 \mathrm{MW}$ where the total installation is $4.756 \mathrm{MW}$. Voltage profiles can also be improved as shown in Fig. 3. Likewise, the channel power loss from the previous power loss is $1.105 \mathrm{MW}$ reduced to $0.234 \mathrm{MW}$.

\section{CONCLUSION}

Of the total number of buses in Penyulang Abang there are 431 Distribution Generators (DG) placed on several buses to improve the overall voltage profile. From the results of running the program (Running) on Abang feeder, the Distribution Generator (DG) is installed on buses 1,5,7 and 302 with a sequence of capacities of $0.374 \mathrm{MW}, 1.894 \mathrm{MW}, 1.988 \mathrm{MW}$ and 0.500 MW where the total installation is $4.756 \mathrm{MW}$.
The previous power loss was $1.105 \mathrm{MW}$, reduced to $0.234 \mathrm{MW}$.

\section{ACKNOWLEDGMENT}

The researcher are very greatful to research and community service of udayana university and ministry of research, technology and higher education with contribution conducting research compotitive grant scheme, so that the research could be conducted.

\section{REFERENCES}

[1] Budiman. A, Breeder, 2010, Genetic Algorithm Multiobjective for Sizing and Placement of Distributed Generator.

[2] Carmen L.T.Borges, Djalma M.Falcao, 2006, Optimal distributed generation for reliability, losses and voltage improvement. ELSEVIER Electrical Power and Energy System28(1006) 4130-420.

[3] SPLN 72. 1987. Spesifikasi Desain untuk Jaringan Tegangan Menengah (JTM) dan Jaringan Tegangan Rendah (JTR). Keputusan Direksi PLN No. 060/DIR/87

[4] Celli G, Ghiani E, Mocci S, Pilo F. A multiobjective evolutionary algorithm for the sizing and siting of distributed generation. IEEE Trans Power Syst 2005;20(2):750-7.

[5] G.N.Koutroiumpezis, A.S.Safigianni, 2010, Optimimum allocation of the maximum possible distributed generation penetration in a distribution network. ELSEVIER Electric Power System Research 80, 1421-1427, June 2010

[6] Sudipta Ghosh, S.P. Ghoshal, Saradindu Ghosh, 2010, Optimal sizing and placement of distributed generation in a network system, ELSEVIER, Electrical Power and Energy Systems 32, 849-85

[7] PT. PLN (persero). 2010. Kriteria Desain Enjiniring Konstruksi Jaringan Distribusi Tenaga Listrik. Buku 1.

[8] Saadat Hadi, Power System Analysis, McGrawHill, International Editions 1999

[9] Aryani Ni ketut, Abdillah M, Negara Y M, and Soeprijanto A, (2011), “ Distributed Generator Using Quantum Genetic Algortihm for Reducing Losses and Improving Voltage Profile", IEEE Conference Publication, pp.108-112

[10] John G. Vlachogiannis a,*, Jacob Østergaard, 2009, Reactive power and voltage control based on general quantum genetic algorithms ELSEVIER, Expert Systems with Applications 36 6118-6126

[11] PT PLN (persero) Distribusi-Bali 